\title{
Atrioventricular discordance with ventriculoarterial concordance: A remaining indication for the atrial switch operation
}

\author{
Igor E. Konstantinov, MD, PhD, ${ }^{a}$ Lillian Lai, MD, ${ }^{c}$ Steven D. Colan, MD, ${ }^{c}$ William G. Williams, MD, FRCSC, ${ }^{a}$ Jia Li, MD,
} $\mathrm{PhD},{ }^{b}$ Richard A. Jonas, MD, ${ }^{d}$ and Richard Van Praagh, MD, ${ }^{c}$ Toronto, Ontario, Canada, and Boston, Mass

I solated ventricular inversion is a very rare anomaly in which there is atrioventricular (AV) discordance and ventriculararterial (VA) concordance (AVD-VAC). ${ }^{1}$ Thus although the aorta arises from the left ventricle and the pulmonary artery (PA) originates from the right ventricle, the systemic and pulmonary circulations are in parallel and not in series. The physiology is that of complete transposition of the great arteries (TGA), but an arterial switch is contraindicated because it would leave the morphologically right ventricle to support systemic circulation.

Six different anatomic types of AVD-VAC have been identified (Figure 1). ${ }^{2}$ All such patients rely on adequate mixing of pulmonary and systemic circulation through either a patent ductus arteriosus or an intracardiac shunt to survive. These anomalies are one of the few indications for the atrial switch operation in the modern era. ${ }^{3}$ Herein we describe the anatomy, corrective operation, and long-term follow-up in these rare patients.

\section{Clinical Summaries}

The 2 institutional databases identified 1085 children who underwent an atrial switch operation. AVD-VAC was present in 1 $(0.18 \%)$ of 560 children who underwent the atrial switch operation from May 1963 through January 2004 in Toronto and $2(0.38 \%)$ of 525 children who underwent the operation from January 1971 through January 2004 in Boston.

PATIENT 1. A girl was given a diagnosis at birth of situs solitus, levocardia, azygos continuation of the inferior vena cava to the right superior vena cava (SVC), left persistent SVC draining into the coronary sinus, AV discordance, VA concordance, large unrestrictive subaortic ventricular septal defect (VSD), and she had signs of pulmonary hypertension. Thus her AVD-VAC was of the $\{\mathrm{S}, \mathrm{L}, \mathrm{S}\}$ type (Figure 1, $A$ ).

In 1986, she had a Mustard procedure and VSD closure at the age of 16 months. The VSD patch was sutured on the morphologically left ventricular side. Intraoperative lung biopsy was performed and demonstrated advanced changes of pulmonary vascu-

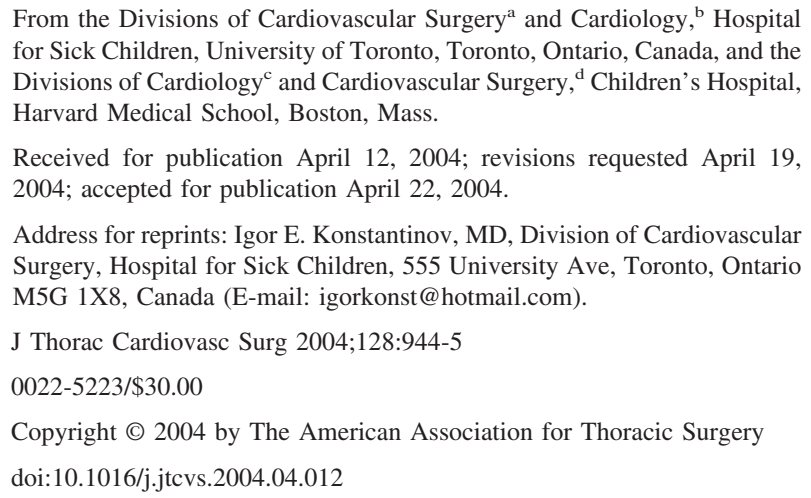

lar disease. She made a good recovery but required a permanent pacemaker implantation for complete AV block. In 2003 (more than 17 years after repair), she was not receiving any medications and had good exercise tolerance. An echocardiogram demonstrated normal morphologically left ventricular size and function, moderate reduction of morphologically right ventricular function, trivial right $\mathrm{AV}$ valve (morphologically mitral) insufficiency, and mild left AV valve (morphologically tricuspid) insufficiency. Unfortunately, she had PA hypertension (estimated PA pressure of 96/60 $\mathrm{mm} \mathrm{Hg).}$

PATIENT 2. A boy born in 1986 was found to have situs solitus, levocardia, AV discordance, VA concordance, and large posterior malalignment VSD, thus resulting in the diagnosis of AVD-VAC of the $\{\mathrm{S}, \mathrm{L}, \mathrm{S}\}$ type (Figure 1, A). He underwent PA banding through a left thoracotomy at the age of 3 weeks.

In 1987, he underwent a Senning procedure, removal of the PA band, and VSD closure at the age of 11 months. The patient was last seen on March 5, 2002 (15 years after repair), when he had good exercise tolerance, remained in normal sinus rhythm, and took no medications.

PATIENT 3. A boy born in 1983 was found to have situs inversus, dextrocardia, azygos continuation of the inferior vena cava to the right SVC, AV discordance, VA concordance, intact ventricular septum, and normally related great arteries, thus resulting in a diagnosis of AVD-VAC of the $\{\mathrm{I}, \mathrm{D}, \mathrm{S}\}$ type (Figure $1, C$ ). He underwent a Senning procedure at the age of 2 weeks.

The child was in normal sinus rhythm, asymptomatic, and receiving no medications and had excellent exercise tolerance in 1997 (14 years after repair). Echocardiography demonstrated normal biventricular function and no AV valvular insufficiency.

\section{Discussion}

The prevalence of AVD-VAC in children who underwent the atrial switch operation in our institutions is low (3/1085 [0.28\%]). However, the importance of these anomalies cannot be overemphasized. An arterial switch is contraindicated because it would convert the physiology of complete TGA to that of congenitally corrected TGA, with the morphologically right ventricle supporting the systemic circulation.

The atrial switch operation provides good long-term results for patients with AVD-VAC by maintaining the left ventricle in the systemic circulation. Our patients were doing well at 17, 15, and 14 years after the atrial switch operation. Unfortunately, one patient has pulmonary vascular disease that predated her repair.

In summary, the AVD-VAC will always remain an important, albeit rare, indication for the atrial switch operation. Awareness of this rare anomaly will provide children with early diagnosis and appropriate surgical procedures. 


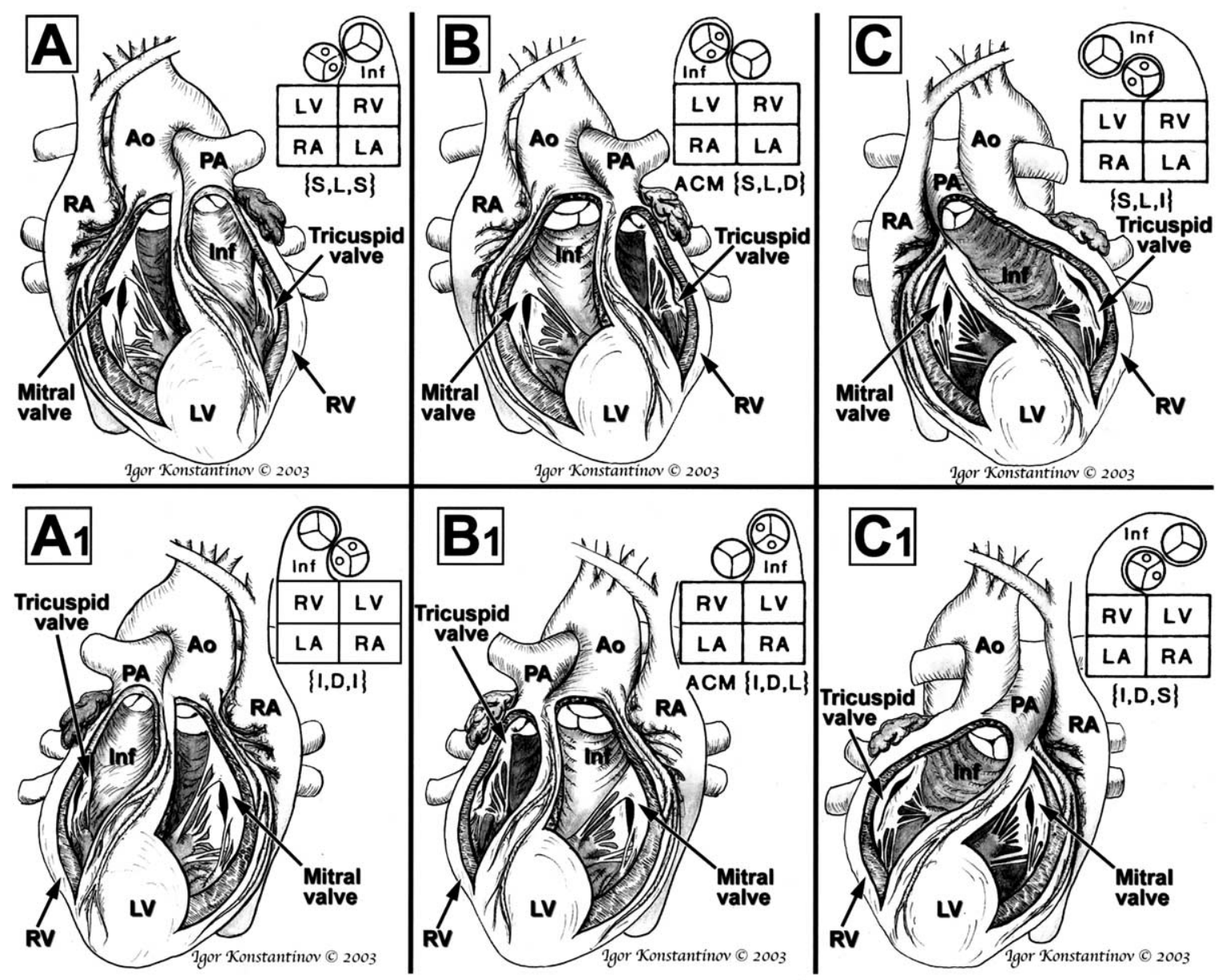

Figure 1. Anatomic types of AVD-VAC. In parentheses the first letter denotes the segmental anatomic set of visceroatrial situs ( $S$, situs solitus; $I$, situs inversus), the second letter denotes ventricular loop ( $D$, D-loop; $L$, L-loop), and the third letter describes relation of the great arteries $(S$, solitus normally related; $I$, inverted normally related; $D$, D-malposition; $L$, L-malposition). When the great arteries are normally related (A, A1, C, and C1), the infundibulum (Inf) is subpulmonary and not subaortic, permitting aortic-mitral fibrous continuity. However, in anatomically corrected malposition (ACM), the infundibulum is subaortic, preventing aortic-mitral fibrous continuity (B and $B 1)$. $A, B$, and $C$ show situs solitus; $A 1, B 1$, and $C 1$ show situs inversus. Ao, Aorta; $L V$, morphologically left ventricle; $P A$, pulmonary artery; $R A$, morphologically right atrium; $R V$, morphologically right ventricle.

\section{References}

1. Van Praagh R, Van Praagh S. Isolated ventricular inversion: a consideration of morphogenesis, definition and diagnosis of nontransposed and transposed great arteries. Am J Cardiol. 1966;17:395-406.

2. Pasquini L, Sanders SP, Parness I, Colan S, Keane JF, Mayer JE, et al.
Echocardiographic and anatomic findings in atrioventricular discordance and ventriculoarterial concordance. Am J Cardiol. 1988;62:125662 .

3. Konstantinov IE, Alexi-Meskishvili VV, Williams WG, Freedom RM, Van Praagh R. Atrial switch operation: past, present and future. Ann Thorac Surg. 2004;77:2250-8. 